\title{
Effects of pile size of artificial reefs on the standing stocks of fishes
}

\author{
Rong-Quen Jan ${ }^{\mathrm{a}}$, Yu-Hsing Liu ${ }^{\mathrm{a}}$, Ching-Yi Chen ${ }^{\mathrm{a}}$, Min-Chang Wang ${ }^{\mathrm{b}}$, \\ Gwo-Shyh Song ${ }^{c}$, Hong-Cheng Lin ${ }^{b}$, Kwang-Tsao Shao ${ }^{\text {a,* }}$ \\ a Institute of Zoology, Academia Sinica, Taipei 11529, Taiwan, ROC \\ ${ }^{\mathrm{b}}$ Marine Fisheries Division, Taiwan Fisheries Research Institute, Keelung 202, Taiwan, ROC \\ ${ }^{\mathrm{c}}$ Institution of Oceanography, National Taiwan University, Taipei 106, Taiwan, ROC
}

Received 7 August 2002; received in revised form 26 February 2003; accepted 7 March 2003

\begin{abstract}
The relationship between production and reef pile size was analysed using standing stocks of fishes surveyed at three established artificial reef (AR) habitats in the subtropical waters off the northern coast of Taiwan during April-August 1999. For a closer look, the fish assemblage was further divided into visitors and residents, and biomass was used as a parameter to represent production. Visitors were characterised by sporadic occurrences and highly variable school sizes. However, large schools (containing more than $200 \mathrm{~kg}$ of biomass) occurred only around small AR piles (consisting of less than 15 units of $2-\mathrm{m}^{3}$ concrete reef). Considering visitors alone, the correlation between biomass and pile size was not significant for the combined data from three sites. Changes in the standing stock of residents followed a clearer trend, and the relationship could be fitted to a sigmoidal equation. This trend shows that collections of the residents tended to increase until the pile reached a size of 20-30 reef units. Thereafter, the increase in biomass slowed, and maximum biomass would eventually be reached only with a further increase in the pile size. Predictions of the efficiency of unit reefs for different pile sizes indicate that a pile consisting of 4-10 units of this type of reef would be most effective in terms of biomass of residents. Nevertheless, a size of 15 units is recommended when the behaviour of visitors is taken into account.
\end{abstract}

(C) 2003 Elsevier Science B.V. All rights reserved.

Keywords: Artificial marine habitats; Coastal fisheries; Fish assemblage; Reef fish residents; Reef fish visitors

\section{Introduction}

Artificial reef (AR) emplacement serves many purposes. It is considered a method for enhancing fishery harvests by providing extra shelter, for restoring habitats by augmenting substrates, and for protecting seabed environments by preventing trawlers from operating in the surrounding waters. In Taiwan, invest-

\footnotetext{
* Corresponding author. Tel.: +886-2-27899545; fax: +886-2-27883463.

E-mail address: zoskt@gate.sinica.edu.tw (K.-T. Shao).
}

ment in AR emplacement has become an important policy in fisheries management; so much so, that more than 170,000 reef units have been constructed and placed at 75 sites in coastal waters over the past 30 years (Lin, 1999). Various materials have been used as ARs. These include ballasted tyres, steel reefs, derelict vessels, and concrete cubes. Concrete cubes are relatively durable, and for ease of fabrication, handling, and mass production, have become major candidates for AR construction in Taiwan in recent years.

In retrospect, despite reef design and construction in Taiwan mirroring many conventional ideas 
(Fitzhardinge and Bailey-Brock, 1989; Grove et al., 1991; Seaman and Sprague, 1991; Pickering and Whitmarsh, 1997), the effectiveness of AR deployment has varied irregularly between sites (Chang and Jan, 1984; Chang, 1985; Chang and Shao, 1988). There has been considerable documentation suggesting that ARs need to be properly placed to function ideally (Gorham and Alevizon, 1989; Grove et al., 1989). To date, reef units were commonly formed into piles or reef sets. Bombace et al. (1994) and Pratt (1994) considered that large reefs with large capacities are likely to attract a greater number of persistent species. While higher biomasses accompany larger reefs, such biomasses are mostly composed of larger, but fewer individuals. By contrast, Bohnsack and Sutherland (1985) and DeMartini et al. (1989) noted greater fish densities and biomasses at small rather than large reefs. Moreover, Ambrose and Swarbrick (1989) considered the edge effect of the reef, address- ing how small reefs might attract fishes from a proportionally larger area due to a higher perimeter-to-area ratio. Since many features of the inhabitants are possibly linked to the size of a reef, planning for the size of a reef set is crucial. In addition, the pile size not only affects the efficiency, but also the total area of influence. That is, with a certain quantity of reef units available, a large pile size would in return lessen the number of reef sets, resulting in a reduction of the total coverage area.

The obvious question of how far the reef arrangement goes toward enhancing AR effectiveness has frequently been asked, but rarely answered. The key to the answer apparently lies in whether the size of the reef pile and the extent to which reef units should overlap with each other can be appropriately set (Pickering and Whitmarsh, 1997; Sheng, 2000). Without empirical data, it is difficult to determine an optimal pile size for a given area. It becomes even more difficult

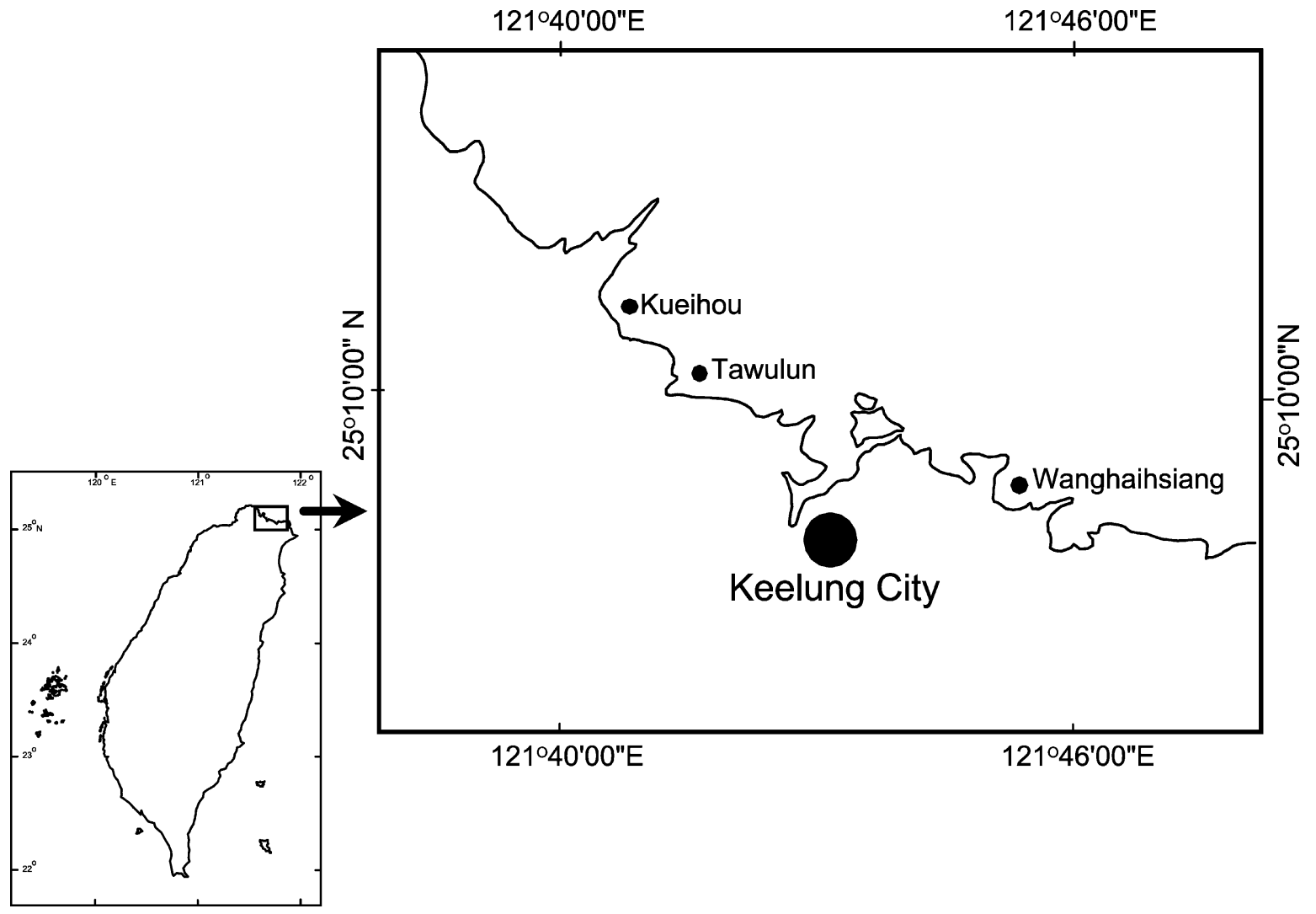

Fig. 1. Map showing the northern coast of Taiwan and Kueihou, Tawulun, and Wanghaihsiang where surveys on ARs were undertaken. 
when the complexity of environmental factors is taken into account. Since plenty of ARs have already been placed in shallow coastal waters around Taiwan, an understanding of the relationships between existing piles and the associated fauna may shed some light on mechanisms structuring the AR fish assemblage. Such information is also crucial for proposals for future reef deployment.

\section{Materials and methods}

\subsection{Study sites}

Underwater investigations were conducted at three established AR habitats, separately around Kueihou, Tawulun, and Wanghaihsiang (Fig. 1), in the subtropical waters off the northern coast of Taiwan during April-August 1999, when the sea was relatively calm. These sites were $2-10 \mathrm{~km}$ apart and $2 \mathrm{~km}$ away from either natural reefs or the seashore. All artificial habitats were established by reef units of $2-\mathrm{m}^{3}$ hollow concrete cubes with holes in them. These ARs were mostly situated on extensive areas of sandy sea floor at 20-30 m depth. The highest pile was built up using four reef units. At each site, various arrangements of reef units were available.

\subsection{Data collection}

Ichthyologists carried out a total of 34 boat dives to census the standing stock of fishes at these sites. Each dive, which used three to four divers with $40 \mathrm{~min}$ of bottom time each, was guided by a side-scanned map presenting detailed AR locations. During the dive, reef units were charted in a water-resistant notebook, and fishes associated with each reef unit were visually identified. Because these divers had undertaken similar surveys at the same sites before, they were capable of distinguishing most fish species at a distance of 2-3 m. The identification of uncertain species was supplemented by pictures taken in situ using underwater cameras and/or videotape, and in a few cases by specimens (all apogonids) collected using clove oil at the end of the survey.

For each fish species, individuals were visually grouped as small, medium, or large in terms of body size (based on fork length), and these groups were separately enumerated. The total biomass of each fish species was estimated from the abundance of each size group and the corresponding wet body weight of specimens (collected elsewhere) as measured in the laboratory.

\subsection{Data analysis}

ARs between which distances were less than $5 \mathrm{~m}$ were grouped into the same pile. (A distance of $3 \mathrm{~m}$ would have led to similar results (unpubl. data).) Thus the ARs observed at each site could be grouped into piles of different sizes. Such a grouping criterion was established mainly based on the site loyalty of residents, particularly apogonids and pomacentrids. For the analysis, data were treated on two scales, namely, site and pile. Jaccard's similarity index was used to compare fish assemblages between sites. For reference, some data collected in previous years were also used, and the similarity index was applied.

Before analysing the effects of pile size on the standing stock, fishes were further grouped into two categories: residents (reef-associated fishes) and visitors (including transients and pelagic fishes in Bohnsack and Talbot (1980) and Bohnsack et al. (1994)). The relationship between the size of the pile and the total fish biomass in that pile was then analysed for each site. To avoid over-weighing the value of small-sized fishes and to overcome the variability due to variable recruitment episodes (Anderson et al., 1989; Bohnsack et al., 1994), we chose to use biomass rather than numerical abundance as the parameter for production in the analysis. Where feasible, the relationship was fitted a sigmoidal equation by assuming that a maximum biomass would eventually be reached with a continued increase in pile size.

\section{Results}

\subsection{Fish assemblages}

Overall, 26,031 individuals of 81 fish species in 30 families were observed at the three sites. Among them, the top 20 most-abundant species contributed $95.6 \%$ to the total numerical abundance (Table 1). Of the 
Table 1

Top 20 most abundant fish species at three sites $^{\mathrm{a}}$

\begin{tabular}{|c|c|c|c|c|c|}
\hline \multirow[t]{2}{*}{ Species } & \multirow[t]{2}{*}{ Category $^{\mathrm{b}}$} & \multirow[t]{2}{*}{ Total number } & \multicolumn{3}{|l|}{ Site } \\
\hline & & & Kueihou & Tawulun & Wanghai hsiang \\
\hline A. nitidus & $\mathrm{R}$ & 4911 & 1531 & 2180 & 1200 \\
\hline P. trilineatum & $\mathrm{V}$ & 4319 & 2089 & 1000 & 1230 \\
\hline C. fumea & $\mathrm{R}$ & 2605 & 1159 & 1181 & 265 \\
\hline P. chrysozona & $\mathrm{V}$ & 2565 & 1991 & 404 & 170 \\
\hline U. tragula & $\mathrm{R}$ & 2225 & 1222 & 693 & 310 \\
\hline A. semilineatus & $\mathrm{R}$ & 1496 & 766 & 0 & 730 \\
\hline R. gracilis & $\mathrm{R}$ & 1480 & 0 & 780 & 700 \\
\hline N. cyanomos & $\mathrm{R}$ & 1052 & 416 & 470 & 166 \\
\hline A. fleurieu & $\mathrm{R}$ & 791 & 354 & 282 & 155 \\
\hline P. chrysopleuron & $\mathrm{R}$ & 786 & 408 & 218 & 160 \\
\hline T. jordani & $\mathrm{R}$ & 470 & 470 & 0 & 0 \\
\hline S. leptolepis & V & 428 & 391 & 37 & 0 \\
\hline P. digramma & $\mathrm{V}$ & 400 & 0 & 400 & 0 \\
\hline A. doederleini & $\mathrm{R}$ & 262 & 60 & 188 & 14 \\
\hline S. vosmeri & $\mathrm{R}$ & 229 & 133 & 71 & 25 \\
\hline C. azurio & $\mathrm{R}$ & 215 & 67 & 92 & 56 \\
\hline P. quadrilineatus & $\mathrm{R}$ & 190 & 20 & 0 & 170 \\
\hline A carangid sp. & $\mathrm{V}$ & 176 & 50 & 73 & 53 \\
\hline Lutjanus kasmira & $\mathrm{R}$ & 153 & 0 & 0 & 153 \\
\hline Heniochus acuminatus & $\mathrm{R}$ & 119 & 80 & 11 & 28 \\
\hline
\end{tabular}

${ }^{a}$ Abundance is based on visual counts of individuals.

${ }^{\mathrm{b}} \mathrm{R}$ : resident; V: visitor (for definitions see text).

81 species observed, $68(84 \%)$ are classified as reef residents. These mainly include apogonids: Apogon doederleini, Apogon fleurieu, Apogon nitidus, Apogon semilineatus, and Rhabdamia gracilis; pomacentrids: Chromis fumea, Neopomacentrus cyanomos, and Teixeirichthys jordani; mullids: Parupeneus chrysopleuron and Upeneus tragula, a nemipterid: Scolopsis vosmeri; and labrids: Choerodon azurio, Halichoeres hartzfeldii, $H$. poecilopterus, and Labroides dimidiatus (Table 1). Reef residents contributed $68.9 \%$ to the total numerical abundance. Another 12 species (15\%) are classified as visitors. These include fusiliers, Pterocaesio chrysozona and Pterocaesio digramma; a haemulid, Parapristipoma trilineatum; a jack, Selaroides leptolepis, and a terapontid, Pelates quadrilineatus (Table 1). Visitors contributed $31.1 \%$ to the total abundance. The only species that was not grouped into either of the above categories is a remora fish Echeneis naucrates. Residents were smaller on average than visitors. Hence residents added only $35.4 \%$ to the total fish biomass in contrast to the $64.6 \%$ by visitors.

\subsection{Similarities between sites}

Twenty-six species occurred at all three sites. Jaccard's similarity indices between fish assemblages from these three sites are Kueihou-Tawulun, 0.43; Tawulun-Wanghaihsiang, 0.43; and Kueihou-Wanghaihsiang, 0.53 , indicating that $43-53 \%$ of the fish fauna are in common between sites. These values are similar to the indices obtained between two subsequent years at each site (Kueihou 1985-1986, 0.41; Tawulun 1992-1993, 0.49; Wanghaihsiang 1994-1995, 0.56). Thus the fish assemblages appear to be as similar between sites as within sites.

\subsection{Relationships between biomass and pile size}

The number of piles observed varied from survey to survey. At Kueihou the largest reef pile is composed of 12 units (Fig. 2). This size is relatively small, compared with those observed at Tawulun (96 units) and Wanghaihsiang (78 units) (Figs. 3 and 4). Nevertheless, at each site, the total biomass of the standing 

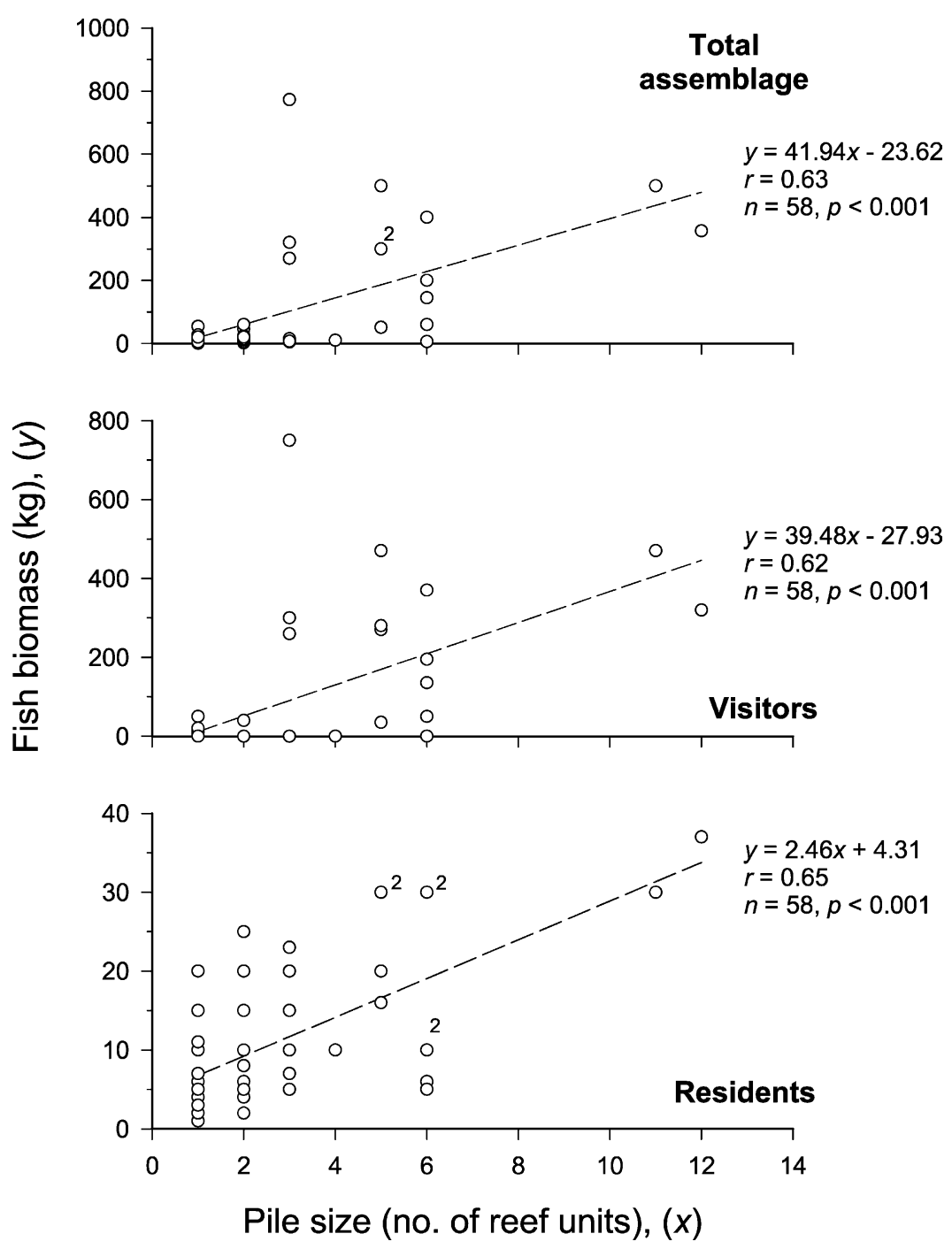

Fig. 2. Linear regression of pile size (i.e., number of reef units) and biomass of the standing stock of fishes in the AR area around Kueihou. Inserted numbers indicate repetitions of the closest data point.

stock seems to vary, to some extent, in accordance with pile size.

\subsubsection{Kueihou}

At Kueihou, visitors occurred in 20 of 58 pile-observations. These include an exceptional massoccurrence of $P$. trilineatum at a small pile (composed of three units). This school added $750 \mathrm{~kg}$ to the total biomass (Fig. 2). The highest biomass among collections of residents was only $40 \mathrm{~kg}$. Thus, when they occurred, visitors constitute the major part of the production of the pile. Overall, there is a positive correlation between pile size and the biomass of the total assemblage ( $r=0.63, P<0.001)$ (Fig. 2). The positive link also holds for the divided assemblages (for visitors: $r=0.62, P<0.001$; for residents: $r=0.65$, $P<0.001)$. Although the correlation coefficients are very close to each other, the slope developed in the linear relationship for residents (i.e., 2.46) was much smaller than that for visitors (i.e., 39.48) (Fig. 2), 

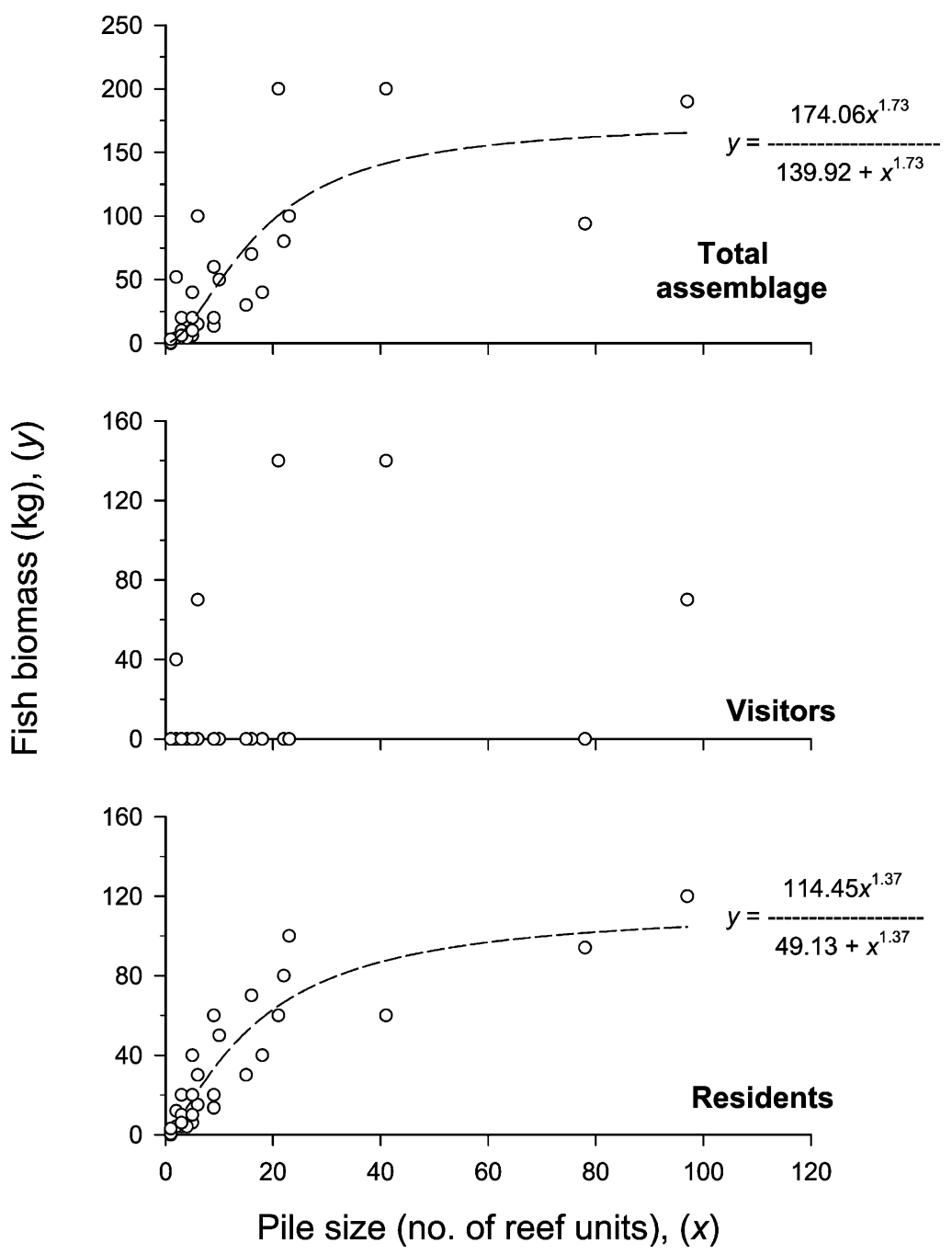

Fig. 3. Relationships between pile size (i.e., number of reef units) and biomass of the standing stock of fishes in the AR area around Tawulun. Where feasible, a sigmoidal equation was fitted to the relationship.

indicating a differential pile-size dependence on the productions of the two categories.

\subsubsection{Tawulun}

At Tawulun, schooling visitors occurred in 5 of 37 pile-observations. The total biomass estimated for each occurrence was within $140 \mathrm{~kg}$, which is smaller than most observations at Kueihou. The biomass of residents reached $120 \mathrm{~kg}$. This is in the same range as that observed at Wanghaihsiang, but it is bigger than that from Kueihou. Relationships between biomass and pile size were analysed and are listed in Fig. 3. In brief, biomass tended to increase rapidly along with increments in pile size before the size reached around 25 reef units. Such a trend applied both to the total assemblage and to residents taken alone. The relationships between standing stock and pile size can be described by the linear sigmoid equations below.

For the total assemblage:

$y=\frac{174.06 x^{1.73}}{139.92+x^{1.73}}$. 

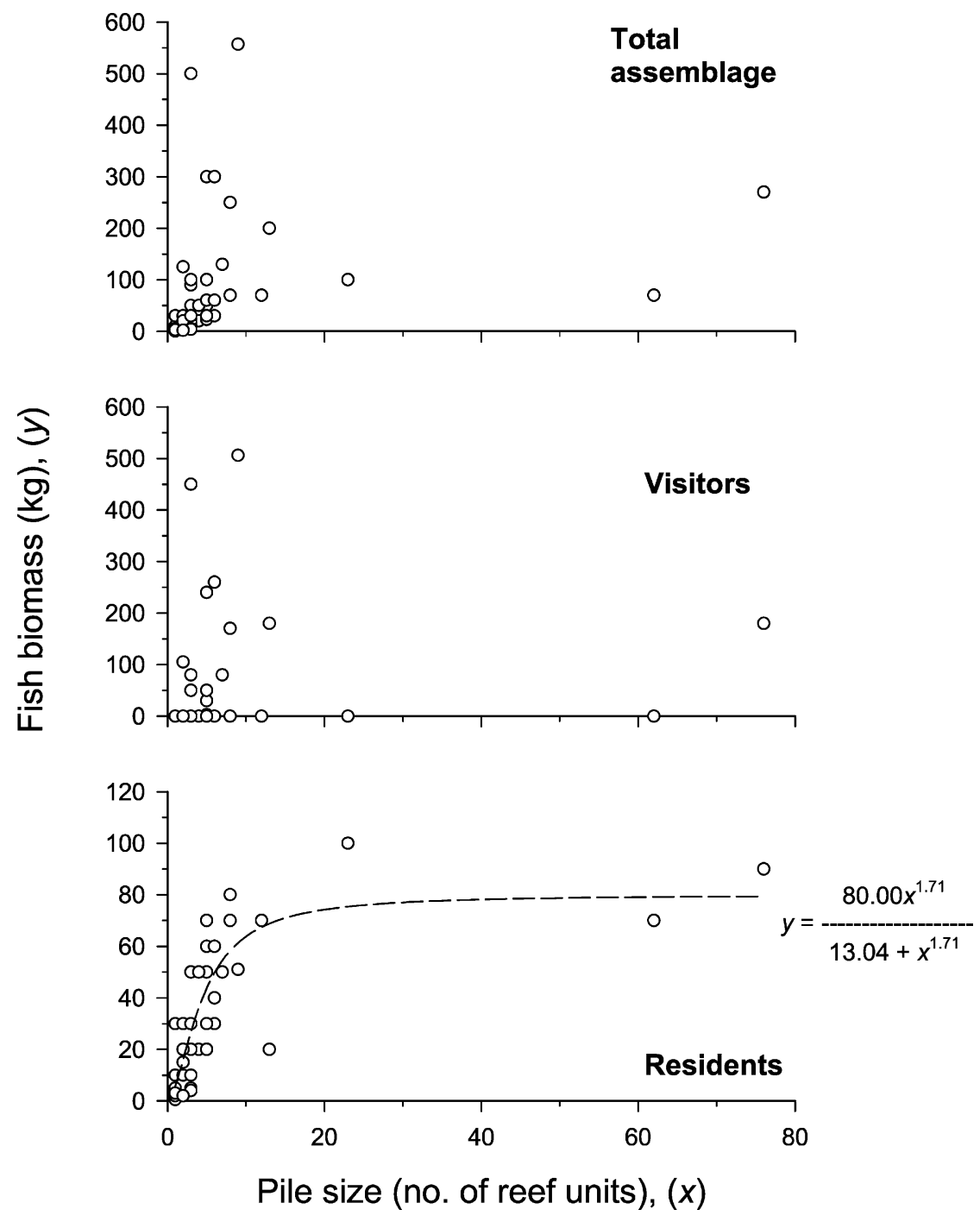

Fig. 4. Relationships between pile size (i.e., number of reef units) and biomass of the standing stock of fishes in the AR area around Wanghaihsiang. A sigmoidal equation describes the relationship for residents.

For residents taken alone:

$y=\frac{114.45 x^{1.37}}{49.13+x^{1.37}}$

where $y$ stands for the biomass in $\mathrm{kg}$ and $x$ for the pile size in number of reef units. The predicted maximal biomass is $114 \mathrm{~kg}$ for residents and $174 \mathrm{~kg}$ for the total assemblage.

\subsubsection{Wanghaihsiang}

At Wanghaihsiang, visitors occurred in 13 of 55 pile-observations. Schools were in the range of between 50 and $670 \mathrm{~kg}$ in biomass (Fig. 4). Residents showed patterns similar to those from Tawulun. However, the rapid increase ceased when the pile size reached 10 units. The sigmoidal relationship was applicable only to residents (Eq. (3)), and the maximal biomass predicted was $80 \mathrm{~kg}$ 

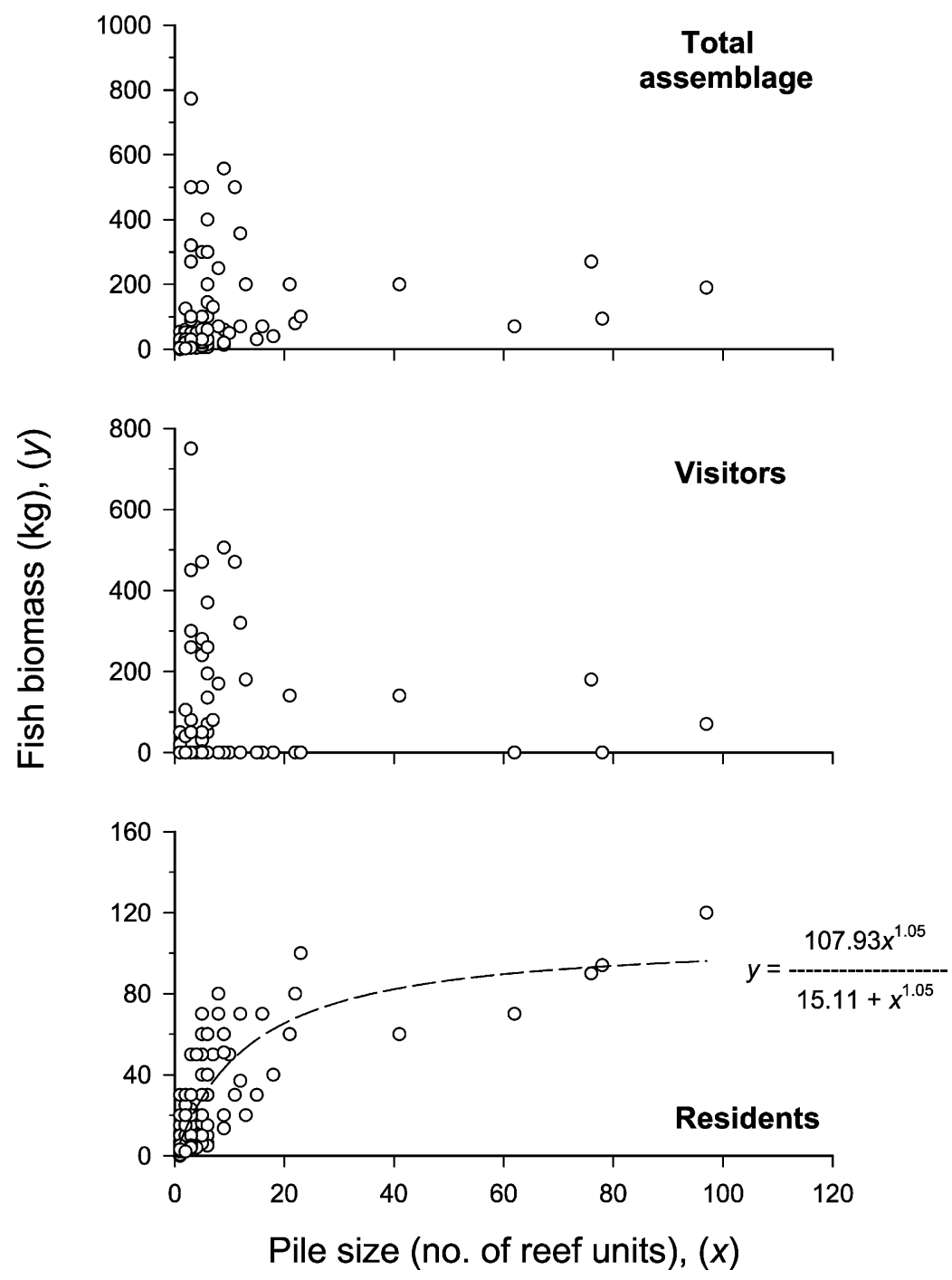

Fig. 5. Relationships between pile size (i.e., number of reef units) and biomass of standing stocks of fishes. Data are combined from Kueihou, Tawulun, and Wanghaihsiang. A sigmoidal equation was fitted to the relationship for residents.

(Fig. 4):

$y=\frac{80.00 x^{1.71}}{13.04+x^{1.71}}$

\subsubsection{Data combined from three sites}

Because fish assemblages from these study sites are similar, an integrated assessment of the relationship was possible (Fig. 5). In general, visitors were characterised by sporadic occurrences. They were observed in only $25 \%$ of piles. Sizes of schools were highly variable, but all large schools (containing more than $200 \mathrm{~kg}$ of biomass) occurred in small AR piles (with sizes of less than 15 units). With only visitors considered, the correlation between biomass and pile size was not significant for the combined data from three sites (Fig. 5). Changes in the standing stock of residents followed a clearer trend. This trend shows that collections of residents tended to increase until the pile reached a size of 20-30 reef units. Thereafter the 
increase slowed. The relationship is shown in Eq. (4). The maximum stock of residents a pile can carry is predicted to be $108 \mathrm{~kg}$ (Fig. 5):

$y=\frac{107.93 x^{1.05}}{15.11+x^{1.05}}$.

\section{Discussion}

When the goal of AR emplacement is fishery enhancement, pile-size management should be seriously considered to ensure a successful outcome (Bohnsack and Sutherland, 1985; Ambrose and Swarbrick, 1989; Campos and Gamboa, 1989; DeMartini et al., 1989; Bohnsack et al., 1994; Bombace et al., 1994). Various optimal pile sizes have been proposed (from 2000 to $5700 \mathrm{~m}^{3}$ or above, as discussed in Bohnsack and Sutherland (1985)). Sato (1985) recommended $400 \mathrm{~m}^{3}$ as a minimum effective size for fishery purposes and an AR bulk volume of about $3000 \mathrm{~m}^{3} \mathrm{~km}^{-2}$ to ensure peak fish harvests.

Based on our results on resident fishes, changes in the efficiency of a reef unit can be elaborated based on Eqs. (2) and (3) for Tawulun and Wanghaihsiang (Fig. 6). The trends show that the efficiency would be highest in a pile with a size of three to four units for Tawulun, and eight to nine units for Wanghaihsiang. For Kueihou, the unit efficiency would be highest with a single reef, but the prediction is valid only for a size less than 12 units. Based on Eq. (4), the overall trend also indicates that a single reef unit would possess the highest efficiency (Fig. 6). The unit efficiency would decline drastically as reefs were added to the pile until the pile size reached about 20 units. A pile size of 30 units is the point where different trends merge in terms of unit efficiency. Before that, the unit efficiency tends to vary drastically both within and between sites. After that the unit efficiency is, by contrast, less variable both within and between sites. Summarising the above information suggests that a pile consisting of 4-10 unit reefs would be most effective in terms of production of residents. However, a size of 15 unit reefs would be recommended when the behaviour of visitors is taken into account. For square concrete reefs observed in the present study ( $2 \mathrm{~m}$ in each dimension), the space available for resident fishes to use as shelter is estimated as $120 \mathrm{~m}^{3}$. For reef piles greater than this size,

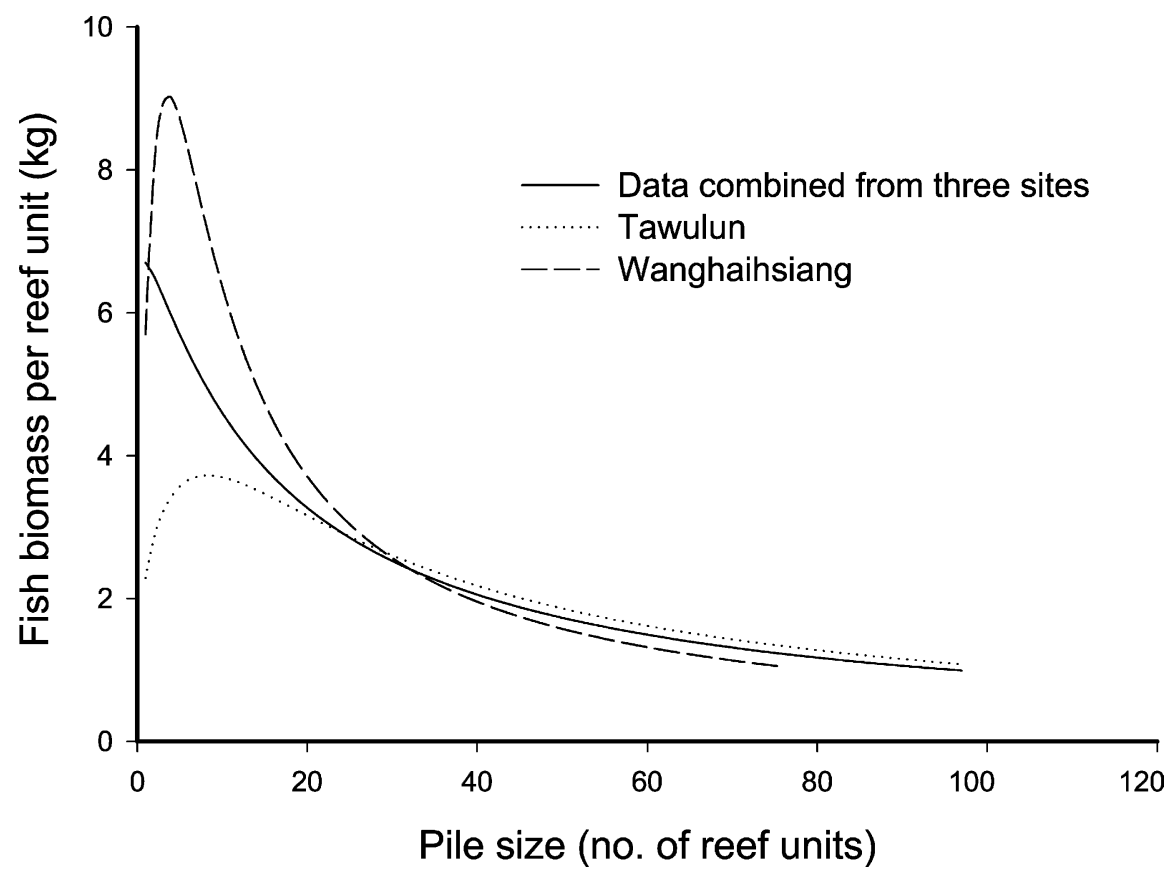

Fig. 6. Predictions of the relationship between the efficiency of the unit reef (indicated as fish biomass per reef unit) and pile size for residents in Tawulun, Wanghaihsiang, and data combined from Kueihou and the above two sites. Predictions are based on Eqs. (2)-(4). 
the efficiency per reef unit decreases. Our optimal size is far smaller in comparison with that of Sato (1985). Reasons for the difference are discussed below.

Our optimal size accounts for both residents and visitors. Most residents in our study were small sedentary fishes, i.e., damselfishes and apogonids; there were relatively few large resident piscivores, i.e., rockfishes and groupers. ARs provide shelter for these small fishes, which stay close to ARs for feeding and evading predators. Once they settle, they seldom migrate. For damselfishes, which spawn demersal eggs (Jan and Ormond, 1992; Jan, 2000), ARs also provide nesting substrates. It is possible that a small pile of ARs might be sufficient for these small fishes to maintain self-sustaining populations. They might gain little extra benefit from inhabiting larger reef piles. If they do, they might, on the contrary, face a higher mortality due to increased competition and predation from larger resident populations and larger individuals (Bohnsack et al., 1994).

Pelagic visitors may use a large and high reef as a landmark (Jessee et al., 1985; Anderson et al., 1989; Sheng, 2000). In the present study the height limit of the reef pile did not seem to affect visitor occurrences because most mass-occurrences of visitors were observed around flat reef piles of the size range of 15 units. By contrast, visitors seldom occurred around the highest pile, which was built up from four reef units. Apart from functioning as landmarks, ARs may provide shelter for diurnal schooling plankton-feeders such as fusilers, $P$. chrysozona and $P$. digramma, and for nocturnal benthic feeders such as the haemulid, $P$. trilineatum. Moreover, pelagic piscivores like the barracuda, Sphyraena flavicauda, and jack, S. leptolepis, might be attracted by the prey availability on ARs (Kock, 1982; Buckley and Hueckel, 1985). Schools of the haemulid, $P$. trilineatum visited reef sites repetitively, indicating a certain degree of site fidelity (pers. observ.). Differences in behaviour may explain the variability in visitor visits to AR sites (Figs. 2-5), and also the difficulties of incorporating visitor information in the pursuit of an optimal pile size.

If a stock is overexploited, it might not be able to supply sufficient offspring for recruitment. In this case, the fish assemblages forming on AR habitats would be limited by recruitment rather than by the availability of habitat. For many years, fishery activities have been intense in waters off the northern coast of Tai- wan. Finding vacant reefs in piles of extremely large size indicates the possibility of recruitment limitations of local fish stocks. However, it also suggests that to enhance effectiveness of ARs, the status of fishery resources should be taken into account in process of AR construction.

Optimal size was based on data collected from similar AR sites established for many years. For future AR emplacements in the same waters, the sizes recommended here should be used because a reef in a pile of 15 units is twice as productive as a pile of 40-50 units (Fig. 6). For other waters, pile sizes should be used with caution (Sheng, 2000). For example, the proposed pile size may not be ideal for managing coral reef fish assemblages, which are more diverse and more spatially variable (Jan et al., 2001). However, the idea that increases in pile size might not be a factor sufficient to promote fishery production in over-exploited waters is worthy of further attention.

\section{Acknowledgements}

We are grateful to Captain F.S. Lee and the crew of Research Vessel Hai-Hung of Taiwan Fisheries Research Institute and Mr. C.H. Hu, owner of the fishing boat Xin-Yu-Fa No. 16, for providing facilities for boat diving. Also, we thank our colleagues C.Y. Hsiao, S.H. Lu, and D.W. Sung for help in data collection and analysis. The study was financially supported by the Fisheries Administration, Council of Agriculture, the Republic of China.

\section{References}

Ambrose, R.F., Swarbrick, S.L., 1989. Comparison of fish assemblages on artificial and natural reefs off the coast of southern California. Bull. Mar. Sci. 44, 718-733.

Anderson, T.W., DeMartini, E.E., Roberts, D.A., 1989. The relationship between habitat structures, body size and distribution of fishes at a temperate artificial reef. Bull. Mar. Sci. 44, 681-697.

Bohnsack, J.A., Sutherland, D.L., 1985. Artificial reef research: a review with recommendations for future priorities. Bull. Mar. Sci. 37, 11-39.

Bohnsack, J.A., Talbot, F.H., 1980. Species-packing by reef fishes on Australian and Caribbean reefs: an experimental approach. Bull. Mar. Sci. 30, 710-723.

Bohnsack, J.A., Harper, D.E., McClellan, D.B., Hulsbeck, M., 1994. Effects of reef size on colonization and assemblage 
structure of fishes at artificial reefs off southeastern Florida, USA. Bull. Mar. Sci. 55, 796-823.

Bombace, G., Fabi, G., Fiorentini, L., Speranza, S., 1994. Analysis of the efficacy of artificial reefs located in five different areas of the Adriatic Sea. Bull. Mar. Sci. 55, 559-580.

Buckley, R.M., Hueckel, G.J., 1985. Biological processes and ecological development on an artificial reef in Puget Sound, Washington. Bull. Mar. Sci. 37, 50-69.

Campos, J.A., Gamboa, C., 1989. An artificial tile-reef in a tropical marine system: a management tool. Bull. Mar. Sci. 44, 757-766.

Chang, K.H., 1985. Review of artificial reefs in Taiwan: emphasizing site selection and effectiveness. Bull. Mar. Sci. 37, 143-150.

Chang, K.H., Jan, R.Q., 1984. Artificial reef project in Taiwan. Tungkang Mar. Lab. Conf. Proc. 1, 51-55.

Chang, K.H., Shao, K.T., 1988. The sea farming projects in Taiwan. Acta Oceanogr. Taiwanica 19, 52-59.

DeMartini, E.E., Roberts, D.A., Anderson, T.W., 1989. Contrasting patterns of fish density and abundance at an artificial rock reef and a cobble-bottom kelp forest. Bull. Mar. Sci. 44, 881-892.

Fitzhardinge, R.C., Bailey-Brock, J.H., 1989. Colonisation of artificial reef materials by corals and other sessile organisms. Bull. Mar. Sci. 44, 567-579.

Gorham, J.C., Alevizon, W.S., 1989. Habitat complexity and the abundance of juvenile fishes residing on small-scale artificial reefs. Bull. Mar. Sci. 44, 662-665.

Grove, R.S., Sonu, C.J., Nakamura, M., 1989. Recent Japanese trends in fishing reef design and planning. Bull. Mar. Sci. 44, 984-996.

Grove, R.S., Sonu, C.J., Nakamura, M., 1991. Design and engineering of manufactured habitats for fisheries enhancement. In: Seaman Jr., W., Sprague, L.M. (Eds.), Artificial Habitats for Marine and Freshwater Fisheries. Academic Press, San Diego, CA, pp. 109-152.
Jan, R.Q., 2000. Resource-limitation underlying reproductive strategies of coral reef fishes: a hypothesis. Zool. Stud. 39, 266-274.

Jan, R.Q., Ormond, R.F.G., 1992. Spawning of damselfishes on the northern coast of Taiwan, with emphasis on spawning site distribution. Bull. Inst. Zool. Acad. Sinica 31, 231245.

Jan, R.Q., Chen, J.P., Lin, C.Y., Shao, K.T., 2001. Long-term monitoring of the coral reef fish communities around a nuclear power plant at southern Taiwan. Aquat. Ecol. 35, 233243.

Jessee, W.N., Carpenter, A.L., Carter, J.W., 1985. Distribution patterns and density estimates of fishes on a Southern California artificial reef with comparisons to natural kelp-reef habitats. Bull. Mar. Sci. 37, 214-226.

Kock, R.L., 1982. Patterns of abundance variation in reef fishes near an artificial reef at Guam. Environ. Biol. Fish. 7, 121-136.

Lin, K.P., 1999. Reports on the conservation of fishery resources. China Fish. Monthly 560, 29-46 (in Chinese).

Pickering, H., Whitmarsh, D., 1997. Artificial reefs and fisheries exploitation: a review of the 'attraction versus production' debate, the influence of design and its significance for policy. Fish. Res. 31, 39-59.

Pratt, J., 1994. Artificial habitats and ecosystem restoration: managing for the future. Bull. Mar. Sci. 55, 268-275.

Sato, O., 1985. Scientific rationales for fishing reef design. Bull. Mar. Sci. 37, 329-335.

Seaman Jr., W., Sprague, L.M. (Eds.), 1991. Artificial Habitats for Marine and Freshwater Fisheries. Academic Press, San Diego, CA, $285 \mathrm{pp}$.

Sheng, Y.P., 2000. Physical characteristics and engineering at reef sites. In: Seaman Jr., W. (Ed.), Artificial Reef Evaluation: With Application to Natural Marine Habitats. CRC Press, Boca Raton, FL, pp. 51-94. 